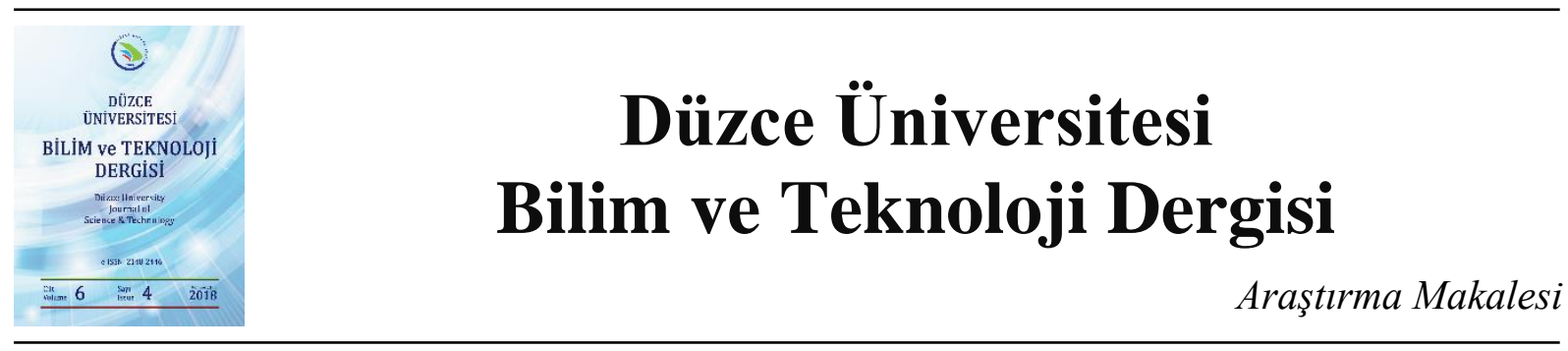

\section{AG Dağıtım Şebekelerinde Kaçak Kullanımın Tespiti ve Otomatik Faturalama İçin Örnek Laboratuvar Çalışması}

\author{
Furkan ÜSTÜNSOY ${ }^{\mathrm{a},{ }^{*}}$, H. Hüseyin SAYAN ${ }^{\mathrm{b}}$, Ali SAYGIN ${ }^{\mathrm{b}}$ \\ ${ }^{a}$ Elektrik-Elektronik Mühendisliği Bölümü, Fen Bilimleri Enstitüsü, Gazi Üniversitesi, Ankara, TÜRKIYE \\ ${ }^{b}$ Elektrik-Elektronik Mühendisliği Bölümü, Teknoloji Fakültesi, Gazi Üniversitesi, Ankara, TÜRKiYE \\ * Sorumlu yazarın e-posta adresi: ustunsoy.furkan@gmail.com
}

\begin{abstract}
ÖZET
Bu çalışma ile akıllı şehirleşmeye katkı sağlayacağı düşünülerek, kaçak enerji kullanımının tespiti, otomatik faturalama ve puant yük talebinin takibi için kullanıcı enerji tüketim verilerinin kablosuz haberleșme ile aktarılması sağlanarak PLC destekli SCADA ile örnek bir laboratuvar uygulaması yapılmıştır. Kaçak enerji kullanımı, arıza tespiti ve hızlı müdahale, uzaktan sayaç okuma ve faturalama, puant yük taleplerinin spesifik şekilde izlenmesi gibi birçok sebep, dağıtım sistemleri için enerji yazılımlarını gerekli kılmaktadır. Bununla birlikte elektrikli araçların kullanımının hızla artışı şehirlerde şarj istasyonlarının varlığını gerekli kılacaktır. Bu durum enerji dağıtım firmaları için tüm şehri kapsayacak bir ağda kompleks topolojilere sahip enerji yazılımlarını zorunlu hale getirecektir. Tüm bu sebeplerle gelecekte akıllı şehirlere geçiş için enerji yönetimi gerekli bir unsur olacaktır.
\end{abstract}

Anahtar Kelimeler: Otomatik faturalama, SCADA, Enerji yazılımı, Akıllı şehirler

\section{A Laboratory Study For Detection of Leakage and Automatic Billing in LV Distribution Networks}

\begin{abstract}
With this study, it is thought that to contribute to intelligent urbanization, a sample laboratory application with PLC supported SCADA was made by transferring user energy consumption data via wireless communication for detection of illegal energy usage, automatic billing and peak load demand. Many reasons, such as leakage energy usage, fault detection and rapid response, remote meter reading and billing, specific monitoring of peak load demands, require energy software for distribution systems. However, the rapid increase in the use of electric vehicles will necessitate the existence of charging stations in cities. This will require energy software with complex topologies in a network that will cover the entire city for energy distribution companies. For all these reasons, energy management will be an essential element for future smart cities.
\end{abstract}

Keywords: Automatic billing, SCADA, Energy software, Smart cities 


\section{GiRiș}

$\mathrm{B}$ irçok ülke için problem olan kaçak elektrik kullanımı, hem maddi kayıp hem de gereksiz enerji kullanımı demektir. Bununla beraber tüketiciler için geleneksel faturalama sistemleri bina bina insan operatörü aracılığıyla yapılır. Bu durum hem gereksiz iş gücü hem de uzun çalışma saatleri gerektirir.

Literatürde, GSM şebekesinin kullanımı yoluyla otomatik sayaç okuma, faturalandırma ve bildirim etkinliğini ve verimliliğini göstermek için GSM GAPMR (Automatic Power Meter Reading) sisteminin çalışma prototipi yapılmıştır [1]. Bir diğer çalışmada $500 \mathrm{kV}$ 'lik bir istasyon, endüstriyel bir güç kontrol odası ve yer altı şebekesi transformatör kasası dahil olmak üzere farklı elektrik-güç-sistem ortamlarındaki kablosuz kanalın istatistiksel karakterizasyonu hakkında kapsamlı bir deneysel çalışma sunulmuş [2], evlerde enerji tüketimini azaltmak için ZigBee iletişimi ve kızıl ötesi uzaktan kumandaları temel alan daha verimli ev enerji yönetim sistemi anlatılmıştır [3]. Transformatör güvenliğini sağlamak amacıyla yapılan çalışmada ise transformatör merkezinde meydana gelen olayların kontrol merkezine ve ilgili kişilere aktarılması için GSM temelli bir uzaktan kontrol sistemi geliştirilmişstir [4]. Ev otomasyon sistemlerinin adaptasyon problemlerini tanımlamak ve ZigBee' nin bu sorunlara çözüm bulma potansiyelinin değerlendirmek için ise esnek ev otomasyon mimarisinin tasarımı ve uygulaması gerçekleştirilmiştir [5]. Bir diğer çalışmada ise, şimdiye kadar sunulan AMR (Automatic Meter Reading) teknolojilerinin kapsamlı bir incelemesi yapılmış ve gelecekteki AMR' lerin üçüncü nesil (3G) iletişim sistemlerinden, DLMS / COSEM (Data Language Messaging Specification/Companion Specification for Energy Metering) standardından ve İnternet Protokolüne dayalı SIP (Oturum Başlatma Protokolü) protokolünden uygulama seviyesinde nasıl fayda sağlayacağı sunulmuştur [6].

$\mathrm{Bu}$ çalışmada, kaçak elektrik kullanımını tespit edebilen ve SCADA yazılımı ile uzaktan enerji akışını durdurabilen bir sistem ve bununla beraber her tüketici için otomatik uzaktan tüketim değeri okuma ve faturalandırma sistemi laboratuvar ortamında gerçekleştirilmiştir. Çalışmada kullanıcı tarafındaki enerji ölçüm verileri kablosuz haberleşme kullanılarak aktarılmıştır. Bu sayede gereksiz kablolamadan kaçınılmıştır. Yapılan bu prototip çalışma şehrin tamamına uygulanır ve tüm tüketici verilerinin ana merkeze akışı sağlanırsa enerji dağıtım sistemi tam anlamıyla takip edilebilir. Alınan verilerle gelecek yük tahmini yapılabilir ve otomatik faturalama sistemi sağlanmış olur. Böylelikle akıllı şebekelerin yaygınlaşması sağlanmış olacaktır.

Akıllı şebekelerinin kontrol ve iletişim yapısı enerji üretim, iletim, dağıtım ve kullanıcı kısmının herhangi birisinde meydana gelen değişikliklere hemen tepki verebilmelerini mümkün kılmaktadır [7]. Dolayısıyla oluşabilecek arızalara anında müdahale edilmesi ile uzun enerji kesintileri minimize edilebilecektir.

\section{Mevcut Kablosuz HaberLeșme YöntemLeri}

Son yıllarda endüstriyel haberleşme sektörü hızla gelişmektedir. Kablosuz haberleşme pek çok otomasyon uygulamasında kullanılmakta ve giderek yaygınlaşmaktadır. Özellikle günümüzde kablolamanın çok mümkün olmadığı uzak nokta uygulamaları ve büyük şehirlerde (metropolitan), maliyet, taşınabilirlik (mobility), karmaşık olmama gibi avantajlardan dolayı daha uygundur. Ancak mevcut kablosuz çözümler, özellikle kapalı çevrimli kontrol uygulaması için, gerçek zamanlı ve 
güvenilirlik gereksinimine göre henüz yeterli bir performans sunmuyor [8]. Fakat daha az gecikmeye ve daha çok güvenilirliğe sahip kablosuz haberleşme teknolojisi geliştikçe bu problemler aşılacaktır. Böylelikle endüstrinin her alanında kablosuz haberleşme yaygınlaşacaktır.

Kablolu izleme sistemleri, pahalı iletişim kablolarının kurulmasını ve düzenli olarak korunmasını gerektirir ve bu nedenle yüksek maliyetlerinden ötürü bugün yaygın bir şekilde uygulanmazlar [9]. $\mathrm{Bu}$ durum özellikle uzak mesafe haberleşme gerektiren sistemlerde geçerlidir. Kablosuz haberleşme teknolojisi kapsama alanı ve veri iletim hızı açısından gelişme gösterdikçe kullanımı daha da yaygınlaşacaktır.

Günümüzde kapsama alanı, veri iletim hızı ve kesintisiz haberleşme durumlarına göre Wireless LAN, WiMAX, Cullular, ZigBee, Bluetooth gibi birçok kablosuz haberleşme yöntemi kullanılmaktadır.

Wireless LAN; IEEE 802.11 standardında olup yerel alanlarda kullanılmaktadır. Veri hızı 1-54 Mbps ve kapsama alanı $1000 \mathrm{~m}$ mesafeye kadar çıkmaktadır. WLAN teknolojisi sürekli olarak iletim hızı, kapsama alanı, güvenlik, hizmet kalitesi ve hareket yönlerinden gelişmektedir [10]. WiMAX; IEEE 802.16 standardında olup geniş bant kablosuz ürünlerin uyumluluğunu ve birlikte çalışabilirliğini desteklemektedir [11]. Ayrıca kapsama alanı $50 \mathrm{~km}$ mesafeye kadar çıkabilmektedir. Cellular (3G/4G); günümüzde sıklıkla kullanılan mobile telefonlar bu haberleşme teknolojisi ile çalışır. Endüstride SCADA ve görüntüleme sistemleri için de sıklıkla kullanılmaktadır. ZigBee; IEEE 802.15.4 standardı üzerine inşaa edilmiştir [12] ve kısa mesafede, düşük güç tüketimi, düşük maliyet ve karmaşık olmayan kablosuz haberleşme teknolojisine sahiptir [13]. Bluetooth; IEEE 802.15.1 standardındadır. Bu teknoloji trafo merkezli otomasyon sistemlerinin bir parçası olarak yerel çevrimiçi izleme uygulamaları için kullanılabilir [14].

Laboratuvar çalışmasında, kullanıcı tarafındaki enerji analizöründen elde edilen veriler IEEE 802.11 (Wireless LAN) standardında olan Phonex marka RAD-2400-IFS model wireless modüller ile iletilmiştir. Wireless modül FHSS (frequency hopping spread spectrum) modülasyon tipinde olup 2.4 GHZ işletme frekansında çalışmaktadır. Ayrıca 16-125-250 kbps hızına sahiptir ve maksimum $1000 \mathrm{~m}$ mesafeye kadar çekim alanına sahiptir. Söz konusu modül Modbus RTU haberleşme protokolünü desteklemektedir. $\mathrm{Bu}$ sayede enerji analizörü ve wireless modül RS-485 arabirim standardı ile haberleşebilmektedir.

$\mathrm{Bu}$ çalışma laboratuvar ortamında yaklaşı $10 \mathrm{~m}$ mesafede gerçekleştirilmiştir.

\section{Sistem Mimarisi ve Kablosuz AĞ Topolojisí}

Bu çalışmada amaca yönelik olarak dağıtım trafosu (DT) ve tüketici tarafına konumlandırılan sistem elemanları bulunmaktadır. Dağıtım trafo (DT) tarafında kullanıcı çıkışlarının enerji ölçümü için enerji analizörü, kaçak kullanımın tespiti ve yük kontrolü için PLC (programlanabilir lojik kontrolör ), görsel ara yüz takibi ve raporlama için SCADA yazılımı ve kullanıcı tarafı enerji verilerinin alınması için wireless modül kullanılmıştır. Tüketici tarafında ise enerji analizörleri ve wireless modül kullanılmıştır. Şekil-1' de sistem mimarisi görülmektedir. Tüketici tarafi enerji analizöründen ölçülen akım, gerilim, aktif güç, reaktif güç, tüketilen aktif-reaktif enerji, güç faktörü, THD-I,THD-V gibi birçok değer Modbus RTU protokolü ile wireless modüle aktarılmaktadır. Wireless modül ise bu verileri dağıtım trafo merkezine aktarmaktadır. Söz konusu veriler PLC' ye oradan da SCADA ara yüz yazılımına 
aktarılmıştır. Dağıtım trafosunda bulunan sisteme aktarılan verilerin merkezi birim istasyonuna aktarılabilmesi için ise GPS modül kullanılmalıdır.

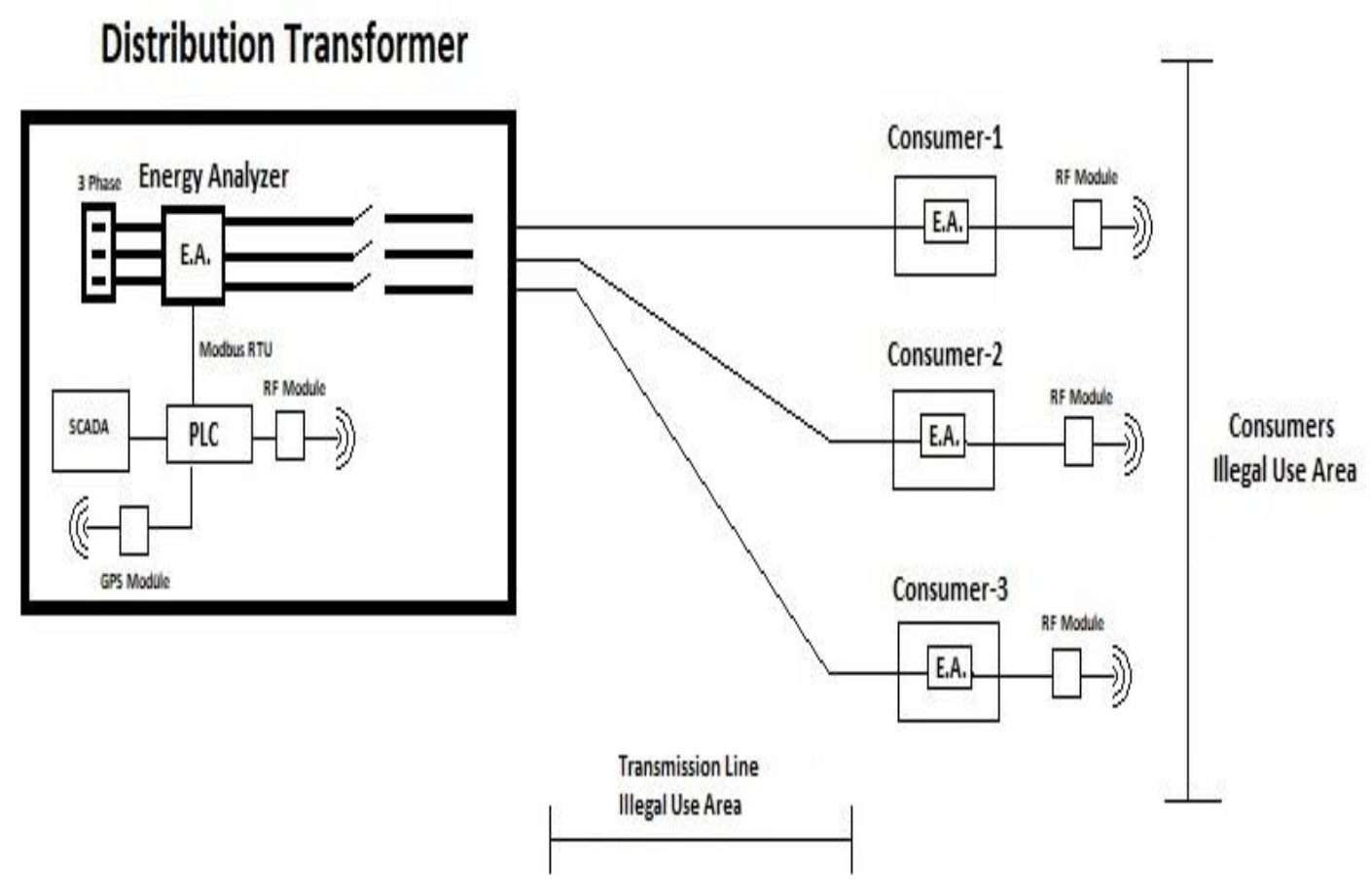

Şekil 1. Sistem mimarisi.

Günümüzde data bus topoloji, yıldız topoloji, ring topoloji, ağaç topoloji, mesh topoloji ve hücresel (cellular) topoloji gibi yaygın kullanılan ağ yapıları mevcuttur [15].

Laboratuvar ortamında yapılan bu çalışmada PLC' ye GPS modüller eklenmesi durumunda, merkezi birim istasyonuna verilerin aktarılması mümkün olacaktır. Bu durum bir şehir için değerlendirildiğinde sistem için en uygun yapı Şekil-2' de görülen gelişmiş yıldız topolojisi olacaktır. Bu topoloji yapısı, esasen tüm şehir genelinde uygulanabilir bir kablosuz sistem mimarisidir.

Öngörülen sistem topolojisi tüketici enerji verilerinin RF (radio frequency) haberleşme ile dağıtım trafo merkezine (DT) oradan da GPS modüller kullanılarak cellular haberleşme ile merkezi birim istasyonuna aktarılmasıdır. Tasarlanan sisteme ek GPS modüller eklenmesi ve merkezi bir istasyon server-SCADA sistemi kurulması durumunda bu topoloji uygulanabilir.

Şekil 2' deki topolojinin uygulanması halinde, merkezi birim istasyonunda bir şehirdeki tüm tüketiciler için otomatik faturalama yapılabilir. Bu durum gereksiz insan gücü ve zaman kaybını önleyecektir. 


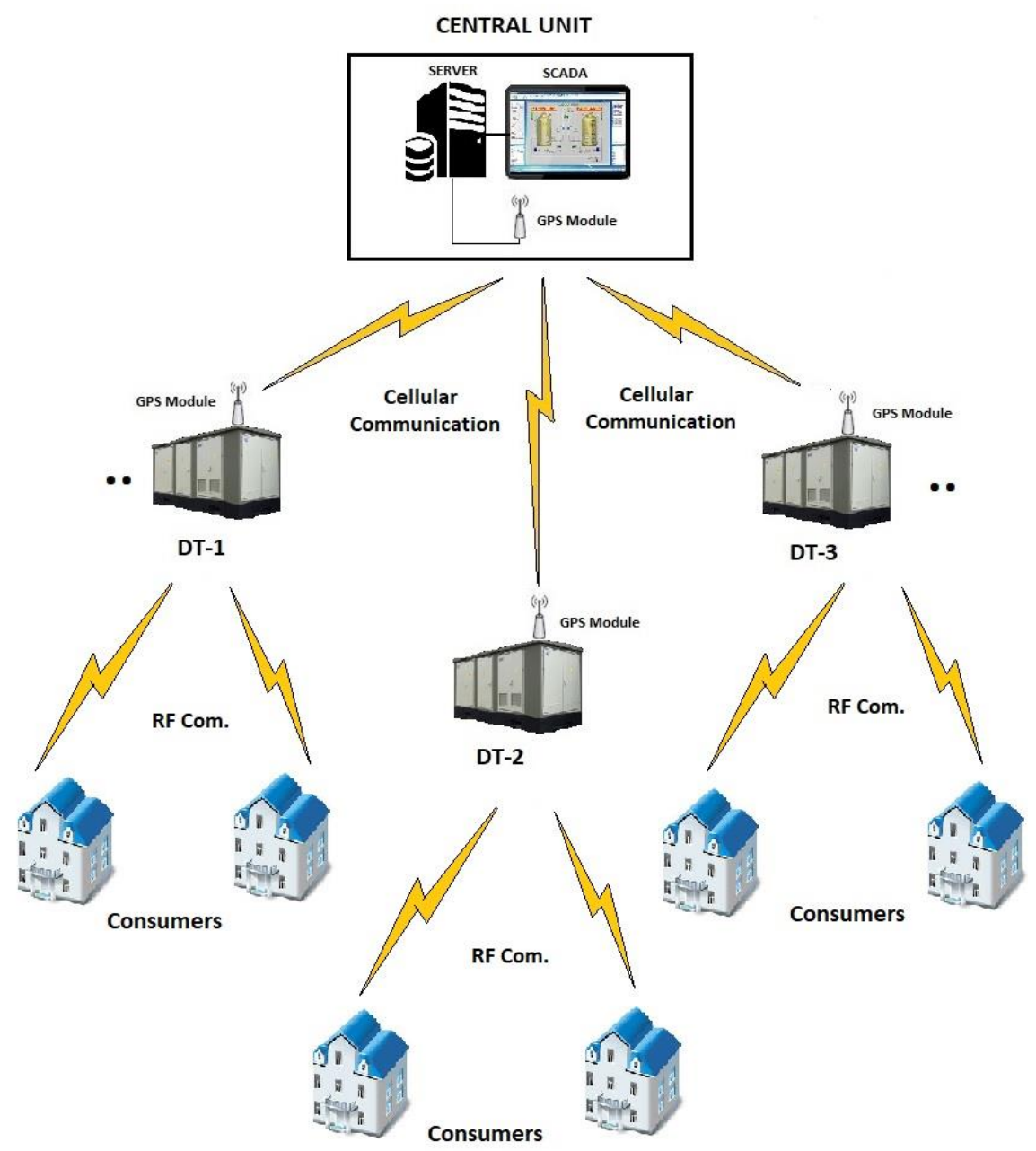

Şekil 2. Kablosuz ăg topolojisi.

Ayrıca dağıtım trafolarındaki PLC programları ile yasadışı kaçak elektrik kullanımının tespiti, şehrin her noktası için mümkün olacaktır. Bununla beraber yine merkezi birim istasyonundaki SCADA yazılımı ile bu durum anlık izlenebilecek ve kayıt altına alınabilecektir. Aynı zamanda tüm tüketiciler için tek merkezden yük kontrolünün sağlanması da mümkün olacaktır. Tüm bunların yanında merkezi serverlarda kayıt altına alınan enerji verileri ile puant yük analizlerinin yapılması ve gelecekte şehrin toplam yük taleplerinin tahmini de mümkün olacaktır.

\section{Kullanilan MATERYAlLER VE SISTEM TASARIMI}

\section{A. KULLANILAN MATERYALLER}

$\mathrm{Bu}$ çalışma otomasyon laboratuvarında küçük güçlerle gerçekleştirilmiştir. Söz konusu çalışma ile Şekil-1'deki sistem topolojisi gerçekleştirilmiş ve sonuçları ortaya konmuştur. Kullanılan tüm malzeme ve yazılımlar endüstriyel ortamlarda kullanılacak şekilde tasarlanmış ve seçilmiştir. 
Enerji tüketim verilerini ölçmek için, günümüzde kullanımı yaygınlaşmaya başlayan fonksiyonel enerji analizörü kullanılmıştır. Söz konusu analizör akım, gerilim, güç faktörü, $\cos \phi$ (ana harmonik için güç faktörü), güç, enerji, frekans, THD-I, THD-V ve belirli mertebeye kadar harmonikleri ölçme kabiliyetine sahiptir. $\mathrm{Bu}$ sayede tüm tüketicilerin enerji kalitesi izlenebilmekte ve kayıt altına alınabilmektedir. Bu kabiliyet özellikle endüstriyel tesislerin enerji kalitesini takip etmek için çok önemlidir.

Uzak noktadan yük kontrolünü sağlamak ve kaçak tespit algoritmasıyla yasadışı kullanımı tespit etmek için Schneider marka M 241 serisi PLC kullanılmıştır. Bu PLC, Modbus RTU, Modbus TCP/IP, Ethernet TCP/IP gibi haberleşme protkolleri ile RS-485, RS-232, Ethernet TCP/IP, USB gibi bağlant1 arabirimlerini desteklemektedir [16].

Uzak noktada tüm sistemi takip etmek, verileri anlık olarak izlemek, gerektiğinde ara yüz yazılımıyla yük kontrolü yapmak ve tüm verileri veri tabanında kayıt altında tutmak için Vijeo Citect marka SCADA yazılımı kullanılmıştır. Yapılan SCADA yazılımı ile çıkabilecek tüm alarmlar, alarm serverda kayıt altına alınabilmektedir.

Tüketici tarafı ölçülen verilerin dağıtım trafosundaki istasyona taşınabilmesi için Phoenix marka RAD2400-IFS model Wireless RF Modül kullanılmıştır. Modbus-RTU ve Modbus-TCP/IP haberleşme protokollerini desteklemektedir [17].

Sistem mimarisindeki tüketici, rezidans yapı ise çok kullanıcılı olacaktır. Bilindiği üzere Modbus haberleşme protokolü 256 adet bağlantıya kadar izin vermektedir. Dolayısıyla bir binada birden fazla analizörün bağlantısı ortak bus ile wireless modüle bağlanarak verilerin iletimi mümkündür.

\section{B. SISTEM TASARIMI}

Laboratuvarda yapılan çalışmada hem trafo tarafı hem de kullanıcı tarafına analizörler konumlandırılmıştır. Kullanıcı tarafında veriler floating point formatında wireless modüle aktarıldı. Slave RF modül ise master RF modüle tüm verileri kablosuz olarak aktarmıştır. Master RF modül ile trafo tarafinda konumlandırılan analizör ortak bus ile PLC' ye bağlanmıştır. Böylelikle tüm veriler floating point formatında PLC somachine yazılımına aktarılmış oldu. PLC ile izleme bilgisayarı arasındaki Ethernet TCP/IP bağlantıyla da tüm enerji verileri varible tag olarak SCADA yazılımına aktarılmıştır.

Şekil 3' te dağıtım trafo tarafi sistem düzeneği ve tüketici tarafı sistem düzeneği görülmektedir. Somachine yazılımında oluşturulan modbus konfigürasyonuyla tüm veriler gerçek zamanlı olarak alınmış böylelikle fazla komut kullanımından kaçınılmıştır. Aktarılan floating point formatındaki veriler, tasarlanan alt program ile desimal olarak real formatına dönüştürülmüştür. Böylelikle elde edilen veriler ilgili alt programlarda kullanılmıştır. 


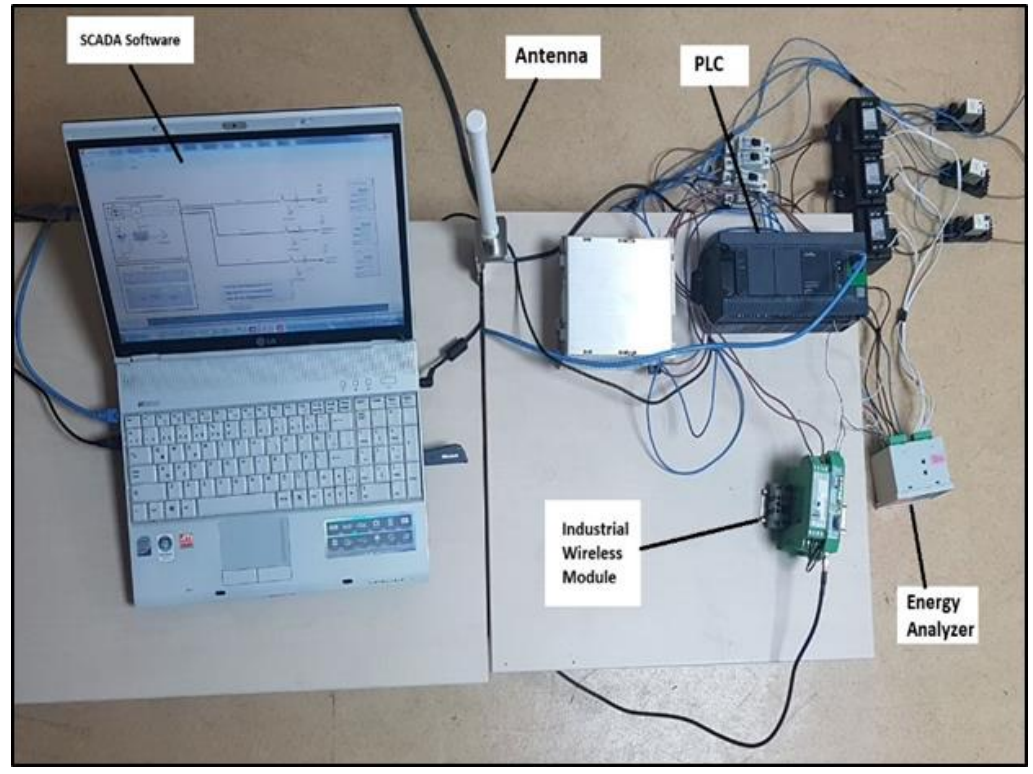

(a)

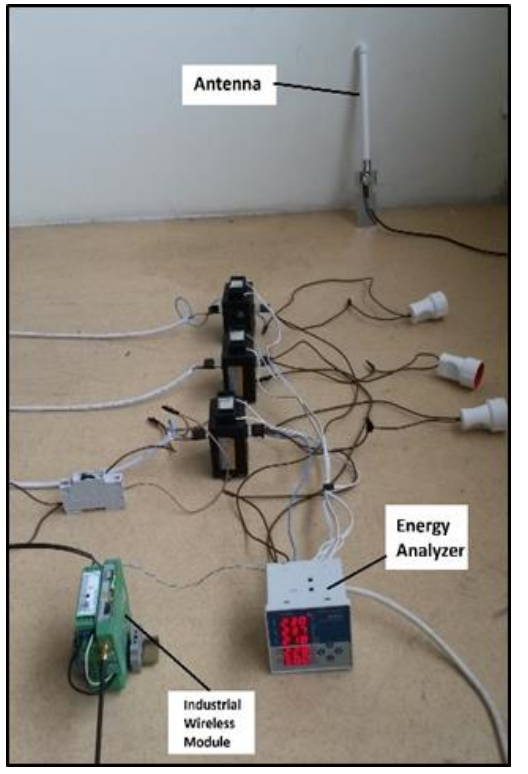

(b)

Şekil 3. (a) Dağıtım Trafo Tarafi Sistem Düzeneği (b) Tüketici Tarafi Sistem Düzeneği.

İletim hatıında veya kullanıcı tarafında yasadışı kaçak kullanımı tespit etmek için yazılım içerisinde alt program oluşturulmuştur. İletim hattı için kaçak tespitinin temeli akım değerlerindeki farklılığın oluşmasına dayanır. Tüm iletim hatları için aynı prensip ele alınmıştır. Haberleşme gecikmelerinden kaynaklı problemlere veya oluşabilecek analizör kalibrasyon hatalarına yönelik önlemler yazılım içerisinde düşünülmüştür. Tüketici tarafı yasa dışı kullanım durumu ise enerji sayacının devre dışı bırakılması ve aynı zamanda trafo tarafi enerji sayacının enerji kullanımını tespit etmesi prensibine dayanır. Tüm bu durumlar PLC somachine yazılımında programlanmıştır. Bununla beraber SCADA arayüzünde yük kontrolü yapılabilmesi için PLC yazılımı içerisinde bir alt program ayrıca oluş̧urulmuştur.

PLC' deki real formatındaki veriler izleme bilgisayarına aktarılarak hazırlanan Vijeo Citect SCADA yazılımı ile anlık izleme, kayıt ve anlık faturalama yapılmıştır.

SCADA sistem yazılımı yapılırken öncelikle I/O server, trend server, alarm server ve rapor server izleme bilgisayarına kurulmuş daha sonra grafik tasarım gerçekleştirilmiştir. Tüm serverlar aynı bilgisayarda çalışacak şekilde tanımlanmış ve kullanılan Schneider marka TM241 serisi PLC için ilgili sürücü kurulumu sağlanmıştır.

Sonraki süreçte ilgili variable tags, trend tags ve alarmlar tanımlanarak tüm grafik ekranların tasarımı gerçekleştirilmiştir. Tasarlanan arayüz yazılımının sistem çalışırken anlık ekran görüntüsü Şekil 4' te verilmiştir. 


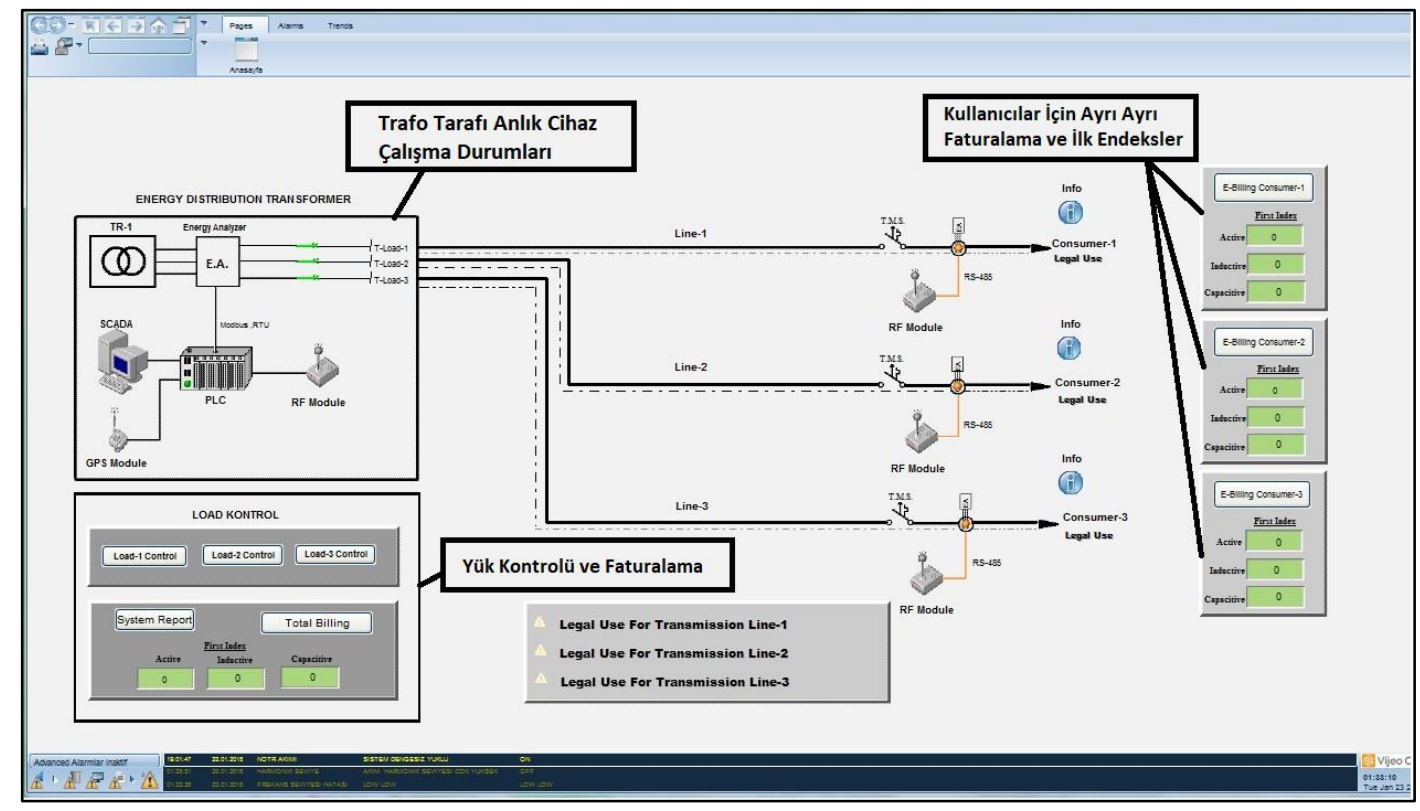

Şekil 4. SCADA Ana Sayfa Görüntüsü.

Şekil 4 'te görüldüğü üzere tüm kullanıcılar için anlık faturalama, operatör aracılığıyla yük kontrolü, yasadışı kaçak kullanım tespiti ve tüm verilerin kayıt altına alınması gecçekleştirilmektedir.

Laboratuvar ortamında oluşturulan sistemde gerçekleştirilen kaçak durumları için SCADA ekranında oluşan uyarı durumları Şekil 5' te görülmektedir.

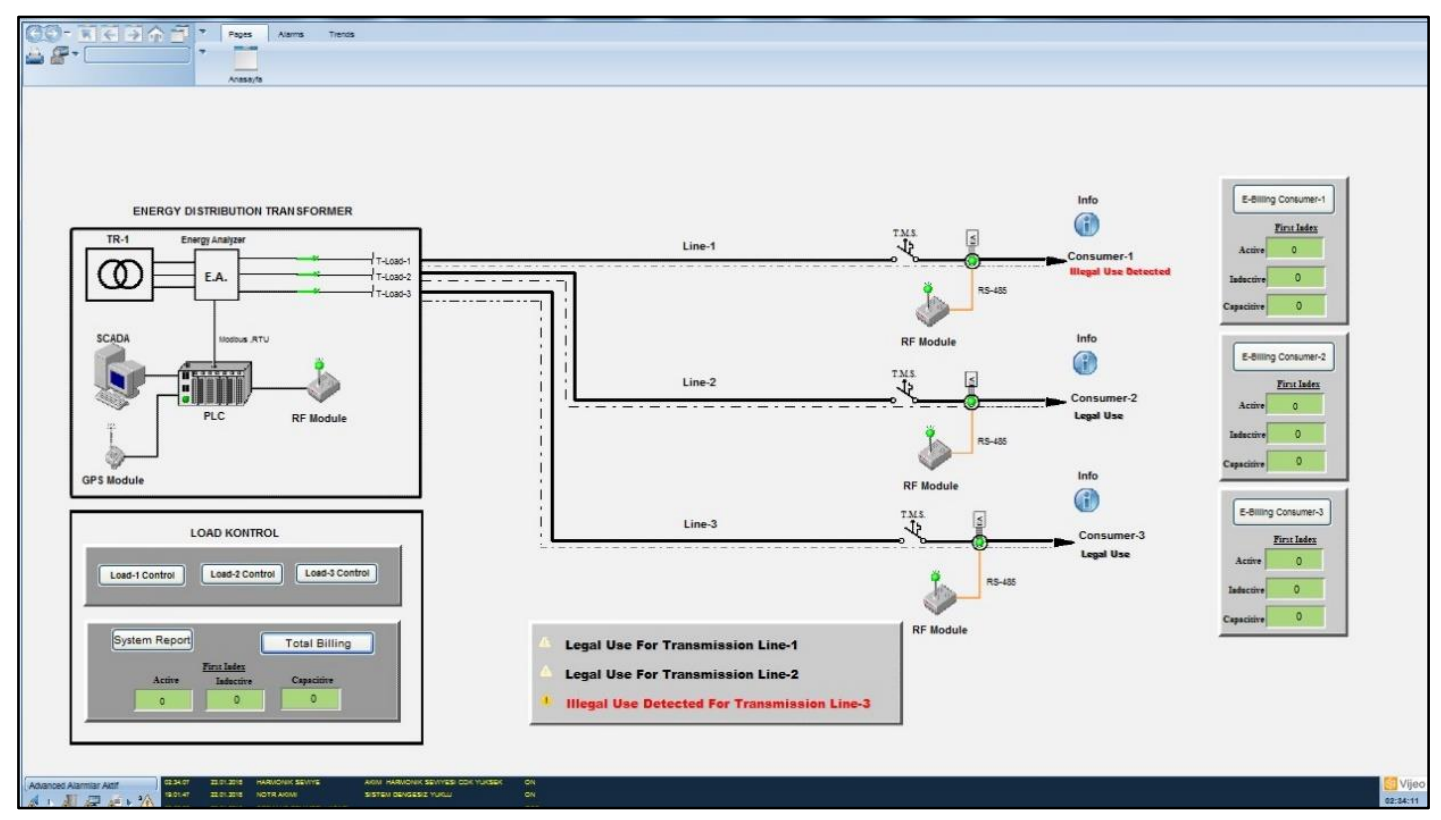

Şekil 5. İletim Hattı Yasadışı Kaçak Kullanım Durumu ve Kullanıcı Tarafı Kaçak Kullanım Durumunun Anlık Ekran Görüntüsü. 
Şekil 5' te iletim hattındaki kaçak durumu ve kullanıcı tarafı kaçak kullanım durumları gösterilmiş olup oluşan bu alarm durumları ayrıca alarm server altındaki databasede geçmişe dönük kayıt altına alınmaktadır. Dolayısıyla oluşturulacak ilave yazılımlar ile kaçak kullanımın bedeli de hesaplanabilir.

Kaçak kullanım durumunda veya arıza durumunda merkezi birim istasyonundaki SCADA ara yüz yazılımı ile yük kontrolü de yapılabilmektedir. Bununla beraber tüm kullanıcılar için ayrı ayrı SCADA ana ekranına yerleştirilen fatura döküm butonu ile Microsoft Excel dosyasında reaktif tüketim bedelleri, toplam tüketim bedeli, reaktif tüketim ceza durumları gibi tüm detayların görülebileceği bir döküm sayfasının alınabileceğini göstermektedir. Şekil 6' da sistem çalışırken alınan döküm sayfası görülmektedir.

\begin{tabular}{|c|c|c|c|c|c|c|c|}
\hline \multicolumn{3}{|c|}{ Electricity Consumption Instant Billing Rate } & \multicolumn{5}{|c|}{ Reactive Power Consumption Cost } \\
\hline \multicolumn{2}{|l|}{ First Index } & 0 & & First Index & Last Index & Total Cons. & \begin{tabular}{|l} 
Instant Percent. \\
\end{tabular} \\
\hline \multicolumn{2}{|l|}{ Last Index } & 58 & Inductive & 0 & 31 & 31 & $53,45 \%$ \\
\hline \multicolumn{2}{|l|}{ Total Consumption (kwh) } & 58 & Capacitive & 0 & 10 & 10 & $17,24 \%$ \\
\hline \multicolumn{2}{|l|}{ Unit Price } & 0,219634 & \begin{tabular}{|l} 
Total Penalty Cost \\
\end{tabular} & \multicolumn{2}{|c|}{3,18611} & & \\
\hline \multicolumn{2}{|l|}{ Consumption Price } & 12,738772 & & & & & \\
\hline & Unit Price & (Unit Price) $\mathrm{x}$ (Total kwh) & Inductive Alarm & \multicolumn{4}{|c|}{ Warning!! } \\
\hline Delivery Cost & 0,110813 & 6,427154 & Capacitive Alarm & \multicolumn{4}{|c|}{ Legal Usage } \\
\hline Service Cost & & 0 & & & & & \\
\hline \multicolumn{3}{|l|}{ Reading Cost } & & & & & \\
\hline Con. Systems Usage Cost & & 0 & & & & & \\
\hline Energy Fund & & 0,6 & & & & & \\
\hline TRT Share & & 1,2 & & & & & \\
\hline Electricity Cons. Tax & & 2,99 & & & & & \\
\hline Excluding Value Added Tax & & 23,955926 & & & & & \\
\hline Value Added Tax $\% 18$ & & 4,31206668 & & & & & \\
\hline Total Billing Cost & & 31,45410268 & & & & & \\
\hline
\end{tabular}

Şekil 6. Fatura Döküm Sayfasl.

$\mathrm{Bu}$ faturalama sistemiyle hem gereksiz iş gücü kullanılmamış oldu hem de anlık olarak faturalamayı merkezi birimlerde yapmak mümkün olmaktadır. Ayrıca SCADA üzerinde tüm tüketicilerin enerji verileri Info sekmesinden izlenebilmektedir. Şekil 7' de sistem çalışırken tüketici 3 için anlık alınan ekran görüntüsü görülmektedir.

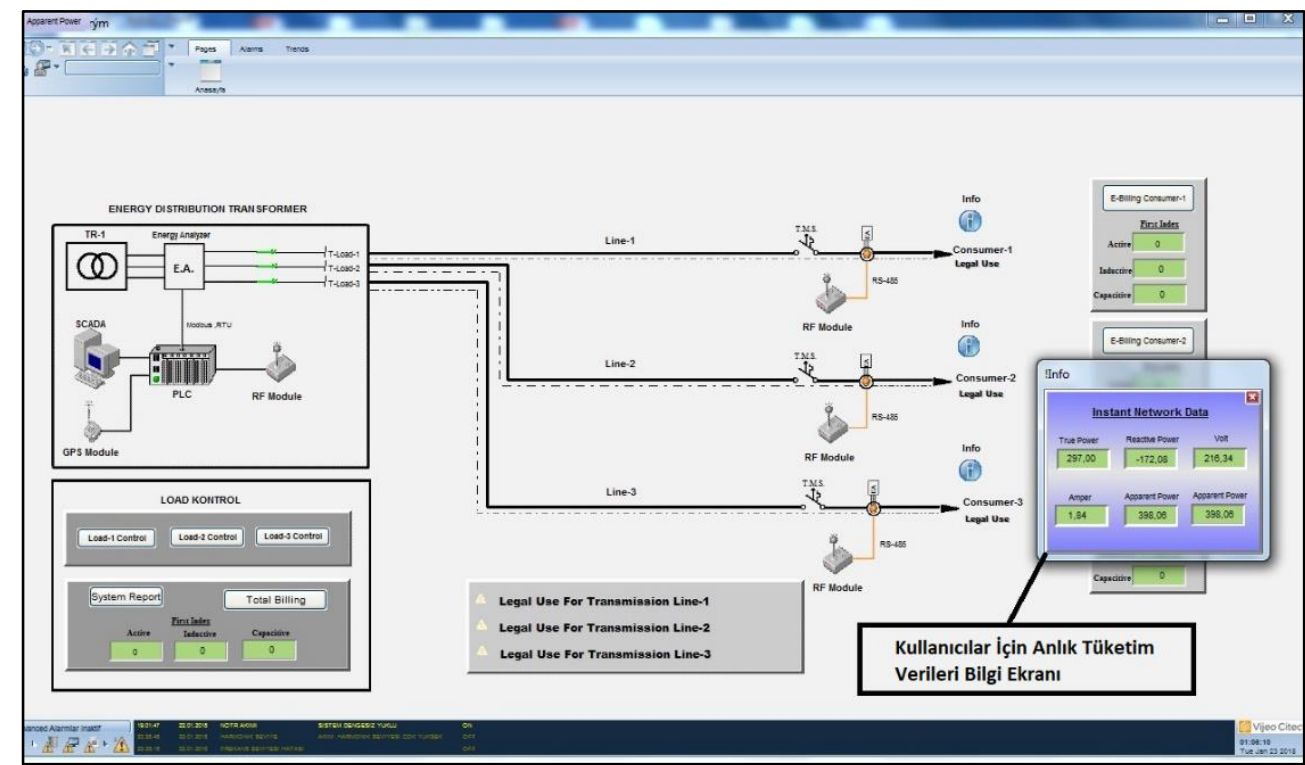

Şekil 7. Enerji Analizinin Anllk Görüntüsü. 
Yapılan tasarım sadece örnek olarak yapılmış olup istenirse info ekranında tüm kullanıcılar için bütün veriler gösterilebilir. Bununla beraber büyük şehir için gerçek uygulama yapılacak olursa SCADA tasarımı tüm kullanıcıları kapsayacak şekilde yapılmalıdır. SCADA ana ekranındaki trendler içerisinde ayrıca grafik olarak anlık görsel takip te sağlanmıştır. Şekil 8' de Tüketici 3 için örnek anlık görüntü verilmiştir.

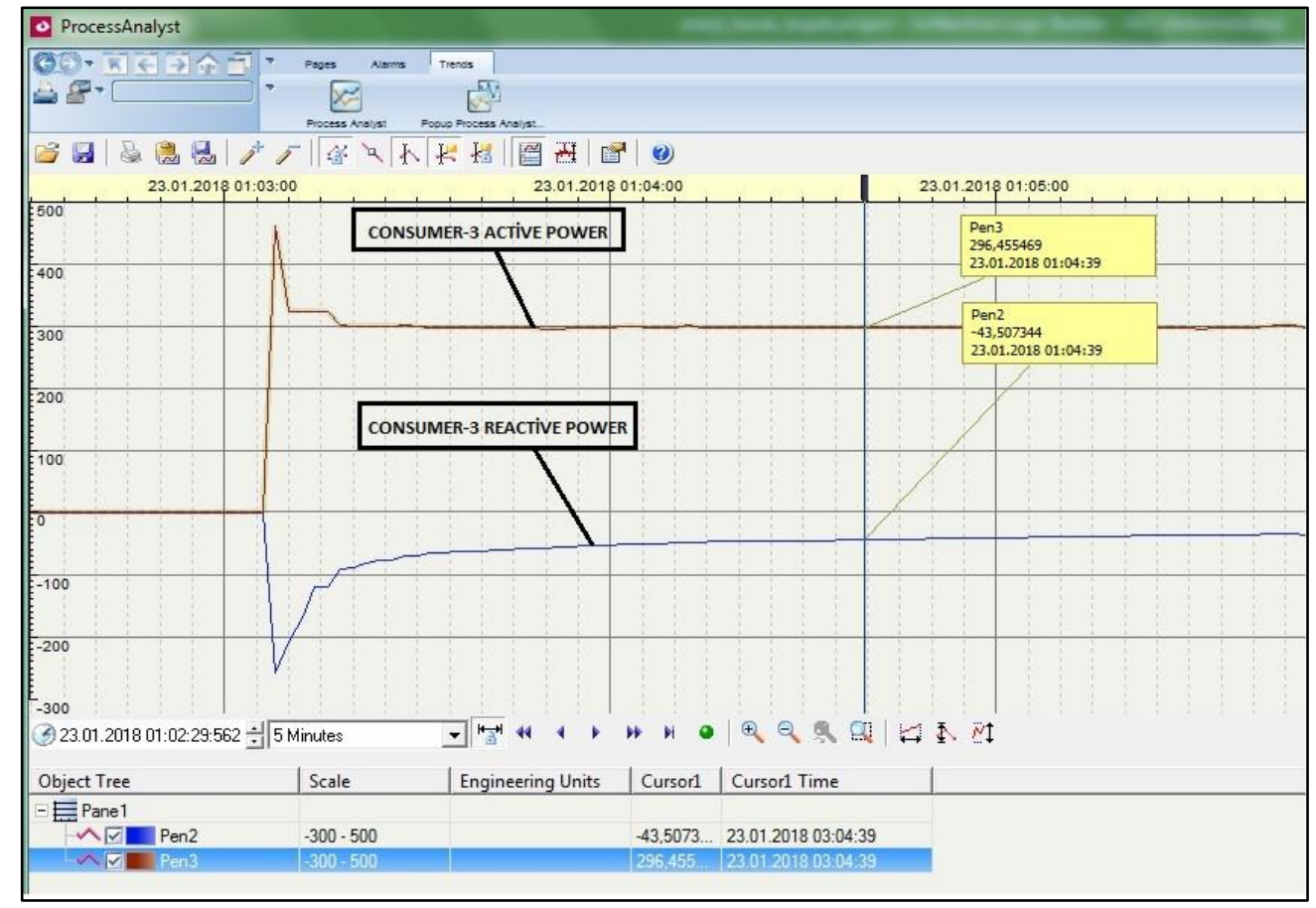

Şekil 8. Tüketici-3 İçin Anlık Trend Görüntü Ekranı.

\section{V.SONUCLLAR VE ÖNERILER}

Bu makale ile özellikle Türkiye için büyük sorun haline gelen yasadışı kaçak elektrik enerji kullanımının tespiti ve otomatik fatura okuma sistemi tasarlanmış ve laboratuvar ortamında küçük güçlerde test edilmiştir. Burada özellikle kablosuz ağ mimarisi ile küçük gecikmelerle, güvenilir veri iletimi dikkat edilmesi gereken husustur.

Tüm sistem laboratuvar ortamında sorunsuz olarak çalıştırılmış ve sonuçları izlenmiştir. Tüketici 3 için iletim hattı kaçak kullanım tespiti ile tüketici 1 için kullanım noktasında kaçak kullanım tespit edilmiştir. Tespit edilen tüm bu durumlar alarm server altındaki database de gerçek zamanlı olarak kayıt altına alınabilmiştir. Ayrıca tüm kullanıcılar için ayrı ayrı otomatik faturalama gerçekleştirilmiştir. Bununla beraber tüm tüketiciler için ayrı ayrı akım, gerilim, güç faktörü, $\cos \phi$, güç, frekans ve harmonikler gibi birçok verinin izlenmesi ve arşivlenmesi sağlanmıştır. Anlık izleme sayesinde şehirlerin elektrik dağıtım sistemleri için minimum arıza oluşumu ve oluşan arızaların anında tespiti de mümkün olacaktır.

Yapılan bu çalışmanın amacı sadece kaçak kullanımın tespiti ve otomatik faturalamaya yönelik değildir. Çalışma, tüm şehir için her bir tüketicinin verilerine tek merkezden anlık ulaşabilmesi, akıllı şehirler ve akıllı şebekeler konularını da kapsamaktadır. Verilerin takibinin yanında yük kontrolünün yapılabilmesi de bu açıdan çok önemlidir. 
Yapılan çalışmanın uygulanabilirliği için maliyet önemli bir kıstastır. Bu çalışmada kullanılan topoloji göz önüne alındığında her bina için yalnızca bir adet endüstriyel wireless modül ve trafo tarafinda da tüm binalar ile aynı bantta haberleşecek bir adet wireless modül ve bir adet PLC kullanımı öngörülmektedir. Tüm trafo bölgelerinin merkeze aktarımı için GPS modül kullanımı öngörülmekte olup tüm GPS modüller için sadece bir şebeke kullanımı mümkündür. Bu sistemin uygulanması durumunda getireceği maddi faydalar düşünüldügünde kurulum maliyeti yüksek olmayacaktır.

Gelecekteki akıllı şebekeler, belirsiz koşullar altında güvenilir ve verimli enerji iletimi için esnek, gözlemlenebilir ve kontrol edilebilir bir şebeke mimarisi gerektirir [18]. Bu sebeple yapılan çalışma akıllı şebekeler ve akıllı şehirler konularına bu açıdan katkı sağlayacaktır.

Günümüz dünyası ulaşım vizyonu elektrikli araçlara doğru yönlenmektedir. Bu sebeple akı1lı şebekelerin önemi giderek artacaktır. Bütünüyle elektrikli araçların yaygınlaşabilmesi için ülkelerin mevcut elektrik alt yapılarının değerlendirilmesi ve geliştirilmesi bununla beraber elektrik tüketiminin dünyada hızla arttığı da göz önüne alınarak elektrik enerji akışının üretildiği ilk noktadan tüketildiği son noktaya kadar izlenmesi ve kontrolü zorunlu olacaktır. Dolayısıyla yapılan bu çalışmanın, SCADA ile tüm şehrin elektrik enerji akışı izlenebileceğinden gelecek projeksiyonda ülkelerin akıllı şebeke projelerine katkı sağlayacağı düşünülmektedir.

Burada özellikle elektrik dağıtım firmalarının akıllı sayaç kullanımına geçerken seçilen sayaçların haberleşme özelliğinin olması ve herhangi bir haberleşme protokolünü desteklemesi gelecekte akı1lı şehirleşme ve akıllı şebeke alt yapısının kurulmasında büyük önem taşımaktadır.

\section{KAYNAKLAR}

[1] H.G. Rodney, C.H. Lee and V.H. Mok, "Automatic Power Meter Reading System Using GSM Network," The 8th International Power Engineering Conference, Singapore, 2007, pp. 465-469.

[2] V.C. Gungor, B. Lu and G.P. Hancke, "Opportunities and Challenges of Wireless Sensor Networks in Smart Grid," IEEE Transactions on Industrial Electronics, vol. 57, no. 10, pp. 3557 - 3564, 2010.

[3] J. Han, C.S. Choi and I. Lee, "More Efficient Home Energy Management System Based on ZigBee Communication and Infrared Remote Controls," IEEE International Conference on Consumer Electronics (ICCE), Las Vegas, NV, USA, 2011, pp. 85-89.

[4] E. Bekiroğlu ve N. Daldal, "Transformatör Merkezlerinin Güvenlik Amaçlı Uzaktan İzlenmesi ve Otomasyonu," e-Journal of New World Sciences Academy, vol. 4, no. 4, pp. 459-470, 2009.

[5] K. Gill, S.H. Yang, F. Yao and X. Lu, “A ZigBee-Based Home Automation System,” IEEE Transactions on Consumer Electronics, vol. 55, no. 2, pp. 422-430, 2009.

[6] T. Khalifa, K. Naik and A. Nayak, "A Survey of Communication Protocols for Automatic Meter Reading Applications," IEEE Communications Surveys \& Tutorials, vol. 13, no. 2, pp. 168-182, 2011. 
[7] Y. Kabalcı ve Kabalcı E., "Akıllı Şebekeler için Kablosuz Enerji İzleme Sistemi Tasarımı ve Gerçekleştirilmesi,” Gazi Üniversitesi Fen Bilimleri Dergisi, c. 5, s.2, ss. 137-145, 2017.

[8] A. Frotzscher, U. Wetzker, M. Bauer, M. Rentschler, M. Beyer, S. Elspass and H. Klessig, "Requirements and current solutions of wireless communication in industrial automation," IEEE International Conference on Communications Workshops (ICC), Sydney, NSW, Australia, 2014.

[9] V.C. Gungor and G.P. Hancke, "Industrial Wireless Sensor Networks: Challenges, Design Principles, and Technical Approaches," IEEE Transactions on Industrial Electronics, vol. 56, no. 10, pp. 4258-4265, 2009.

[10] F. Siddiqui, S. Zeadally and K. Salah, "Gigabit Wireless Networking with IEEE 802.11ac: Technical Overview and Challenges," Journal of Networks, vol. 10, no. 3, pp. 164-170, 2015.

[11] V. Gazis, M. Görtz, M. Huber, A. Leonardi, K. Mathioudakis, A. Wiesmaier, F. Zeiger, and E. Vasilomanolakis, "A Survey of Technologies for the Internet of Things," International Wireless Communications \& Mobile Computing Conference (IWCMC), Croatia, 2015.

[12] A. Mahmood, N. Javaid and S. Razzaq, "A review of wireless communications for smart grid," Renewable and Sustainable Energy Reviews, no. 41, pp. 248-260, 2015.

[13] L. Quan-Xi and L. Gang, "Design of remote automatic meter reading system based on ZigBee and GPRS," Proceedings of the Third International Symposium on Computer Science and Computational Technology (ISCSCT '10), Jiaozuo, P. R. China, 2010, pp. 186-189.

[14] P. P. Parikh, M. G. Kanabar and T. S. Sidhu, "Opportunities and Challenges of Wireless Communication Technologies for Smart Grid Applications," Power and Energy Society General Meeting, Providence, RI, USA, 2010.

[15] O. Uysal and Z.A. Misırl1, "Physical Topologies in Computer Networks," Recent Advances in Applied Mathematics and Computational and Information Sciences, no. 2, pp. 377-381, 2009.

[16] Anonim, (6 Mart 2018). [Online]. Erişim: www.schneider-electric.com.

[17] Anonim, (6 Mart 2018). [Online].Erişim: www.phoenixcontact.com.

[18] B.B. Alagoz, A. Kaygusuz and A. Karabiber, "A user-mode distributed energy management architecture for smart grid applications,” Elsevier Enerjy Journal, no. 44, pp. 167-177, 2012. 